\title{
Symmetrization of Closure Operators and Visibility
}

\author{
Horst Martini and Walter Wenzel \\ Fakultät für Mathematik, Technische Universität Chemnitz, D-09107 Chemnitz, Germany \\ \{martini, walter\}@mathematik.tu-chemnitz.de \\ Received March 9, 2005
}

AMS Subject Classification: 06A15, 05B35, 06B05, 51D20, 52A05

Dedicated to the Memory of Gian-Carlo Rota

\begin{abstract}
For an arbitrary set $E$ and a given closure operator $\sigma: \mathcal{P}(E) \rightarrow \mathcal{P}(E)$, we want to construct a symmetric closure operator $\hat{\sigma}: \mathcal{P}(E) \rightarrow \mathcal{P}(E)$ via some - possibly infinite - iteration process. If $E$ is finite, the corresponding symmetric closure operator $\hat{\sigma}$ defines a matroid. If $E=$ $\mathbb{R}^{n}$ and $\sigma$ is the convex closure operator, $\hat{\sigma}$ turns out to be the affine closure operator. Moreover, we apply the symmetrization process to closure operators induced by visibility.
\end{abstract}

Keywords: closure operator, symmetric and finitary closure operator, lattices, matroid, visibility problem, illumination problem, convexity

\section{References}

1. V. Boltyanski, H. Martini, and P. Soltan, Excursions into Combinatorial Geometry, SpringerVerlag, New York, 1997.

2. B.A. Davey and H.A. Priestley, Introduction to Lattices and Order, Cambridge University Press, Cambridge, 2002.

3. A.W.M. Dress and W. Wenzel, Matroidizing set systems - a new approach to matroid theory, Appl. Math. Lett. 3 (2) (1990) 29-32.

4. B. Ganter and R. Wille, Formale Begriffsanalyse, Springer-Verlag, Heidelberg, 1996.

5. H. Hadwiger, Ungelöste Probleme, Nr. 38, Elem. Math. 15 (1960) 130-131.

6. A. Higuchi, Lattices of closure operators, Discrete Math. 179 (1-3) (1998) 267-272.

7. R.E. Jamison, A development of axiomatic convexity, In: Technical Report no. 48, Clemson University, Math., (1970) pp. 15-20.

8. R.E. Jamison, A perspective on abstract convexity: classifying alignments by varieties, In: Convexity and Related Combinatorial Geometry, D.C. Kay and M. Breen, Eds., Marcel Dekker, (1982) pp. 113-150.

9. B. Korte, L. Lovász, and R. Schrader, Greedoids, Springer-Verlag, Berlin, 1991.

10. H. Martini and V. Soltan, Combinatorial problems on the illumination of convex bodies, Aequationes Math. 57 (1999) 121-152. 
11. H. Martini and W. Wenzel, A characterization of convex sets via visibility, Aequationes Math. 64 (2002) 128-135.

12. H. Martini and W. Wenzel, An analogue of the Krein-Milman theorem for star-shaped sets, Beiträge Algebra Geom. 44 (2) (2003) 441-449.

13. H. Martini and W. Wenzel, Illumination and visibility problems in terms of closure operators, Beiträge Algebra Geom. 45 (2) (2004) 607-614.

14. K. Meyberg, Algebra, Teil 2, Carl Hanser-Verlag, München-Wien, 1976.

15. F.A. Valentine, Visible shorelines, Amer. Math. Monthly 77 (1970) 146-152.

16. R. Webster, Convexity, Oxford University Press, Oxford, 1994.

17. N. White, Theory of Matroids, Cambridge University Press, Cambridge, 1986. 